\title{
Erratum to: Euvoluntariness and just market exchange: moral dilemmas from Locke's Venditio
}

\author{
Ricardo Andrés Guzmán¹ ${ }^{1}$ Michael C. Munger²
}

Published online: 18 June 2015

(C) Springer Science+Business Media New York 2015

\section{Erratum to: Public Choice (2014) 158:39-49 DOI 10.1007/s11127-013-0090-x}

There was an omission from the "Acknowledgments" section. The authors apologize for the error. The corrected "Acknowledgments" is below.

Acknowledgments This paper was presented as the Otto "Toby" Davis Lecture at George Mason University, October 18, 2012. We thank Jonny Anomaly, Neera Badhwar, Geoffrey Brennan, Jo Anne Burgess, Juan Pablo Couyoumdjian, Craig Davis, José de la Cruz Garrido, Gerald Gaus, Michael Gillespie, Ruth Grant, Eugenio Guzmán, Daniel Houser, John Jackson, William Keech, Dan Klein, David Levy, Lotta Moberg, Dan Moseley, James Otteson, Carlos Rodríguez-Sickert, Geoffrey Sayre-McCord, and David Schmidtz for helpful comments. Guzmán acknowledges support from Fondecyt Grant No 1120387 and Anillo Conicyt Grant SOC-1101, and Munger acknowledges support for the Center for the Study of Public Choice at George Mason University, and the family of Otto "Toby" Davis. Errors that remain are the responsibility of the authors.

The online version of the original article can be found under doi:10.1007/s11127-013-0090-x.

Michael C. Munger

munger@duke.edu

Ricardo Andrés Guzmán

rguzman@udd.cl

1 Centro de Investigación en Complejidad Social and Facultad de Gobierno,

Universidad de Desarrollo, Santiago, Chile

2 Departments of Economics and Political Science, Duke University, Durham, NC, USA 